Original Research Paper

\title{
Understanding Preferences for Nature Based and Sustainable Tourism: The Role of Personal Values and General and Specific Environmental Attitudes
}

\author{
Paola Passafaro, Francesca Cini, Vittoria Diaco, \\ Ornella Schirru, Aurora Boison, Virginia Gasparri and Simona Giannantoni \\ Department of Developmental and Social Psychology, Sapienza University of Rome, Italy
}

Article history

Received: 06-10-2014

Revised: $15-12-2014$

Accepted: 03-08-2015

Corresponding Author:

Paola Passafaro

Department of Developmental and Social Psychology,

Sapienza University of Rome, Italy

E-mail: paola.passafaro@uniroma1.it

\begin{abstract}
This paper reports the results of a study which investigated the social psychological correlates of people's preferences for sustainable and unsustainable tourism activities. Two-hundred-eightytwo participants from two Italian cities responded to a questionnaire which recorded their tourism preferences, their general proenvironmental attitudes and values and their specific attitudes towards sustainable tourism. Results showed positive correlations among the constructs considered. Groups of participants differing in their tourism preferences were also identified and the paper discusses the way in which the social psychological variables considered here may be used to plan adequate strategies and management instruments able to address crucial issues of sustainability in tourism, including, for example, tourists' ecological behaviours "on site" and their educational needs.
\end{abstract}

Keywords: Environmental Attitudes, Environmental Values, Tourist Preferences, Sustainable Tourism, Ecotourism

\section{Introduction}

Tourism is a resource-consuming activity which contributes around $5 \%$ to global (CO2) emissions (UNWTO, 2007). "The huge infrastructural and resource demands of tourism (e.g., water consumption, waste generation and energy use) can have severe impacts upon local communities and the environment" (Shah et al., 2002). For these reasons many international organisations have been supporting the development of sustainable forms of tourism, that is, forms of tourism which lead to management of all resources in such a way that economic, social and aesthetic needs can be fulfilled while maintaining cultural integrity, essential ecological processes, biological diversity and life support systems (WTTC and UNWTO, 1996; Bramwell and Lane, 1993). Various studies have suggested the application of marketing strategies able to increase the overall demand (i.e. market request) for these forms of tourism. These strategies are typically based on the identification of different typologies of tourist on the base of, for example, their preferences and expectations and on planning vacations able to meet the needs of each category identified (for eg. Archer and Wearing, 2002; Dolnicar and Leisch, 2008; Gilmore and Simmons, 2007). However, increasing people's interest in these forms of tourism and obtain their satisfaction is only part of the problem. In particular, in a more comprehensive perspective, tourists' preferences and expectations should be relevant not only as factors affecting the overall tourism demand, but also as aspects influencing the sustainability of the individual's choices during the vacation (once on site) and after the vacations (once back home). Nevertheless, little is known about which factors can prompt people to endorse social and environmental responsibility while making their tourism choices before, during and after the vacation, while their educational needs in this sense are rarely addressed. Studies in environmental psychology have suggested that people's general pro-environmental attitudes and values tend to play a role in directly or indirectly prompting sustainable behaviours in various domains (Bamberg and Möser, 2007; Steg et al., 2014; Stern and Dietz, 1994). Moreover, the literature showed the importance of considering the specific attitudes towards the target behaviour or issue (Staats, 2003). In the tourism domain, only a few studies have addressed the role of environmental attitudes and values on sustainable tourism choices, while no study has, for example, investigated the possible role of the specific attitudes towards sustainable tourism, defined here as the individual's willingness to endorse social and environmental responsibilities while on holiday. Hence, 
it would be sensible to reach a deeper understanding of the role of these factors in people's sustainable tourism preferences and choices and use them in order to forecast their educational needs concerning sustainability in tourism. The manuscript will discuss the way in which environmental psychology can contribute to overcome the limits of the marketing literature on sustainable tourism and disentangle the role of the various motivational factors involved in sustainable tourism choices.

\section{From Sustainable Tourism to Ecotourism:} Balancing Ideal Programmatic Definitions with the Need of Practical Applications

One of the most cited definitions of sustainable tourism was provided by the World Tourism Organization which sees it as "tourism which leads to management of all resources in such a way that economic, social and aesthetic needs can be fulfilled while maintaining cultural integrity, essential ecological processes, biological diversity and life support systems" (WTTC and UNWTO, 1996; see also Bramwell and Lane, 1993). Implicit in this view is the idea that sustainable tourism is alternative to mass tourism which causes dangerous imbalances in the tourism/environment system. While, at the beginning, the aim of sustainable tourism was to reduce such imbalances to zero, later on, many academics expressed their skepticism as to whether the competition among the various components of the tourism/environment system could be actually reduced. As Hunter (1997) stated, "in reality trade-off decisions taken on a day-to-day basis will almost certainly produce priorities which emerged to skew the destination area based tourism/environment system in favor of certain aspects" (Hunter, 1997). This is not surprising given that sustainable tourism shares the same difficulties of implementation faced by the more general concept of sustainable development from which it was derived (see Hunter, 1997 for a discussion on this point); and it is reasonable, if one agrees with Hardy and Beeton (2009) who concluded that "sustainable tourism is a goal which is applicable to all forms of tourism". Hence a more realistic and "adaptive" approach was suggested which considers sustainable tourism as an "over-arching paradigm which incorporates a range of approaches to the tourism/environment system within destination areas" (Hunter, 1997). One of these approaches concerns the so called 'ecotourism. Ecotourism is an all-naturebased form of tourism in which the main motivation of tourists is the observation and appreciation of nature as well as of the traditional cultures prevailing in natural areas. Ecotourism: contains educational and interpretation features; is generally, but not exclusively, organised for small groups by specialised and small locally-owned businesses; minimises negative impacts on the natural and socio-cultural environment; generates economic benefits for host communities; creates jobs and income opportunities for local communities; and increases awareness both among locals and tourists about biodiversity protection principles (UNWTO, 2002; see also Donohoe and Needham, 2006; Donohoe and Lu, 2009; UNWTO, 2001; 2002 for reviews on definitions of ecotourism and discussions on this topic). Ecotourism represents a concrete and clearly identifiable manifestation of sustainable tourism and "[...]has experienced a rapid increase of popularity over the last 20 years" (Hardy and Beeton, 2009). For this reason, most of the studies reporting empirical investigations on tourists' appraisal of sustainable forms of tourism have focused on ecotourism. Such contributions have provided important information concerning tourists' preferences, expectations and satisfaction with this form of tourism, but reveal some limits which deserve to be further discussed.

\section{Limits of the Marketing Studies on Tourism Sustainability}

Most of the studies reporting empirical investigations on tourists' appraisal of ecotourism have addressed it from the perspective of market segmentation (e.g. Beh and Bruyere, 2007; Galloway, 2002; Kibicho, 2006; Marques et al., 2010). Such literature has the merit of having provided crucial evidence regarding the variety of motivational factors able to orient tourists' choices in this domain. For example, Lindberg (1991) identified four main population segments potentially interested in the ecotourism market. The author placed these segments along the continuum of "hard-soft" ecotourism (Laarman and Durst, 1987) and distinguished them into: (1) hardcore nature tourists-scientific researchers or people somehow interested in deepening their scientific knowledge; (2) dedicated nature tourists-people travelling to natural protected areas in order to understand the natural and cultural history of the local environment; (3) mainstream nature tourists-people visiting famous nature sites; and (4) casual nature tourists-people occasionally encountering nature during their vacations (see Galley and Clifton, 2004). Weaver and Lawton (2002), instead, distinguished among: (1) harder ecotourists-travellers who hold strong proenvironmental attitudes, prefer travelling in small groups, appreciate long trips with little comfort, like practicing physically challenging activities, autonomously organise their vacation and conceive travelling as an existential experience; (2) softer ecotourists-travellers who appreciate ecotourism as well as certain forms of traditional tourism; they prefer travelling in large groups for short trips having multiple goals; they do not like physical activities and require comfort and quality from the tour operators and travel agency that they use in order to organise their holiday; 
(3) structured ecotourists-travellers who show, like the "harder ecotourist", a strong pro-environmental concern as well as a certain interest for physically challenging activities and who, nevertheless, appreciate like "softer ecotourists", short trips for multiple purposes, in large groups with all facilities. Cini et al. (2012), investigating a sample of 365 high school students, highlighted three main profiles of young tourists (wellness tourists, vacationer tourists and ecotourists), whose characteristics parallel some of those identified by previous research work. Understanding differences in tourists' needs and expectations can help tour operators and local managers in structuring tourist offers able to capture the attention of various potential ecotourism consumers and increase their satisfaction with the tourism experience. A limit of this investigations, however, is that ecotourism is treated here merely as a "product" that needs to be promoted on the tourism market thanks to the identification of types of consumers potentially interested in "purchasing" customized tourist packages (Diamantis, 1998). As a matter of facts, these studies limited the discussion of the implications of their results to those strictly concerning the market potentialities; that is, to the potentialities that the information drawn offers to the elaboration of customer care strategies and effective promotional communication campaigns. This corresponds to a rather traditional (and restricted) view of tourists' role which relegates them to be passive spectators of the sustainability process. Such view seems more in line with the concept of "maintainable tourism" than with that of "sustainable tourism (Hardy and Beeton, 2009). Indeed the former entails a "minimalist" application of the sustainability principles (Weaver, 2005) where the involvement of tourists in social and ecological issues is reduced and in general, the conservation goals are "site-specific and status-quo oriented" (Weaver, 2005). More "comprehensive" forms of ecotourism (and, by extension, of sustainable tourism), should instead lead tourists to be more involved in the sustainability goals of the tourism experience, while the conservation aims should be directed to "enhance" local sustainability according to a long term perspective (Weaver, 2005). In this sense, while, on the one hand, the market segmentation literature has provided useful insights concerning the "consumerism side" of ecotourism, on the other hand it has failed to address other facets and implications of the tourists experience. The point does not concern the technique itself, but the goals of the analysis, the variables investigated and the way in which such variables are used for profiling tourists. Arguably, if the goals of such technique are set more in line with, for example, the tenets of environmental social marketing ${ }^{1}$ (Finisterra do Paco and Barata Raposo, 2010; Howestine, 1993; Jesson, 2009; Kotler, 1982; Kotler and Roberto, 1989; McKenzie-Mohr, 2000a, 2000b; Tabanico and Schultz, 2007), they could lead to the identifications of other needs besides those linked to the personal appreciation and satisfaction for the tourist experience. In particular, for example, profiling tourists according to their preferences, values and attitudes could be used also in order to forecast their environmental behavior once on-site and to address their educational needs concerning sustainability issues. Indeed, this latter is a feature often neglected by the existing literature on both sustainable tourism and ecotourism, despite the primary role it plays among their declared goals (Donohoe and Needham, 2006; Weaver, 2005). In order to address such issue, however, it is important to clarify some crucial aspects concerning the controversial relationship between consumers choices and their environmental attitudes.

Psychology's Role in the Ecotourism Studies: Sheading More Light on the Controversial Relationship Between Tourism Choices and Environmental Attitudes

The empirical and theoretical research work conducted in the domain of environmental psychology has shown how a distinction exists between the motivations (or intents) which guide the individuals in their everyday behaviors and the results of such behaviours in terms of environmental impact (see Stern, 2000). Indeed, as Stern (2000) has pointed out, "through human history the environmental impact has largely been a by-product of human desires for physical comfort, mobility, relief from labor, enjoyment, power, status, personal security, maintenance of tradition and family and so forth and of the organizations and technologies humanity has created to meet these desires. Only relatively recently has environmental protection become an important consideration in human decision making". As tourists' choices and behaviours have become environmentally significant, the existence of such discrepancy has to also be considered relevant in the tourism domain and deserves to be better investigated. More specifically, as tourists' choices and behaviours have proven to be linked to a variety of motivational factors (see Cohen, 1974; 2004; Crompton, 1979; Kim et al., 2006; Pearce and Packer, 2013; Plog, 1987), it cannot be assumed that considerations regarding sustainability represent the main factors "pushing" all individuals towards sustainable choices in this domain. For example, contrary to what had been previously found (see, e.g., Butler and Fenton, 1987; Hvenegaard and Dearden, 1998; McFarlane and Boxall, 1996; Uysal et al., 1994), Blamey and Braithwaite (1997) noted how "the majority of potential ecotourists do not have particularly green values". This means that the increase in ecotourism demand recorded in the last decades might not necessarily be linked to an increased interest in environmental issues. As Weaver (2005 pointed out, there are cases in which "the natural environment serves as a convenient setting for facilitating other kinds of 
motivations including relaxation and hedonism in the case of the 3S (sea, sun and sand) and thrill-seeking and risk-taking in the case of outdoor adventure". More in general, it is well known in environmental psychology that, for example, most people appreciate natural areas because of their restorative power: in many cases they serve as a refuge from the stressful stimulations of the everyday social life (cf., e.g., Berto, 2005; Bonnes et al., 2011; Hartig, 2004; Kaplan and Kaplan, 1989; Korpela et al., 2002; Scopelliti and Giuliani, 2004; 2005). Moreover, green areas were found to convey the idea of a pure, clean and healthy environment (Henwood and Pidgeon, 2001), connotations which are able per se to attract the attention of people looking for high-quality environments. In addition, by adopting an "elemental" focus on the environment, many people appreciate, for example, ecotourism vacations because they are attracted by specific charismatic elements of the local flora and fauna (see Weaver, 2005, for a review). Finally, as long as ecotourism represents an alternative form of vacation with restricted diffusion, some people may be attracted by the opportunity of distinguishing themselves from the mass tourists by participating in an extravagant and elite vacation (cf. Weiler and Richins, 1995). Hence it is important to keep in mind that, for example, a person cannot be assumed to hold pro-social and proenvironmental values (and cannot be expected to behave accordingly) just because he/she has chosen to experience an ecotourism vacation. This might be irrelevant for a pure market-oriented perspective (where selling the tourist product is the sole goal), but it is crucial for a sustainable development approach because, for example, sustainable tourism can only be reached if tourists' choices and behaviours "on site" support sustainability. Environmental psychology can play an important role in this sense by disentangling the different roles of the various motivational factors involved.

\section{Aims and Hypotheses}

The general aim of this study was to analyse the relationship between general and specific proenvironmental attitudes and values, on the one hand and preferences for sustainable and unsustainable typologies of tourism activities and services, on the other. Our major hypothesis was that preferences for more sustainable activities and services would correlate positively with altruistic and pro-ecological values, general pro-environmental attitudes and positive specific attitudes towards sustainable tourism.

Another aim of this study was to identify groups of people differing in their tourism preferences and to show how environmental attitudes and values could be of help in providing practical and managerial implications that included, but at the same time moved beyond, the issues of customer demand and satisfaction. In particular, we wanted to show how implications could be derived to be used by local managers to forecast the possible ecological behaviour of tourists (once on site) and to set up the most appropriate educational strategies.

\section{Method}

\section{Study Design}

The research design was articulated in two phases. In phase 1 a qualitative study was conducted in order to identify a set of tourist activities and services referable to sustainable and unsustainable forms of tourism. This phase was necessary in order to build a measurement instrument (a structured questionnaire) to be used in a quantitative study during phase 2 . Phase 2 was thus dedicated to hypothesis testing and to the exploration of the relationships among the considered constructs.

\section{Method of Phase 1}

Goals - Phase 1 of the study identified and selected a set of tourist activities and services referable to two main broad categories: (1) low (social and environmental) impact activities/services, typical of sustainable forms of tourism; and (2) high (social and environmental) impact activities/service, typical of conventional or mass tourism. Some nature based vacations, such as for example 'ecotourism' (tourism in natural protected areas) are by definition typical forms of sustainable tourism. Ecotourism was thus chosen here as the prototype for a sustainable form of tourism and its features were used as parameters to select the set of sustainable tourism activities/services. This is because: (i) its characterising features can be clearly identified on the basis of a consistent number of scientific publications existing in the literature and (ii) ecotourism exists as a specific and clearly identifiable market product offered by specialised tour operators and travel agencies. The criteria for selecting the ecotourism activities were identified following the theoretical perspectives proposed by Weaver (2005; see also Weaver and Lawton, 2007) and Donohoe and Needham (2006). In particular, it was postulated that an ecotourism holiday should be one that simultaneously holds at least the three following characteristics:

- Contact with nature (possibly within a protected area, but not exclusively) and outdoor activities with a reduced impact on the local environment and population

- Contact with the local communities and their culture (history, traditions, economy, society, etc.) 
- An overall reduced impact on the physicalgeographical and social-economical local environment (compared to other more conventional or mass tourist activities)

Other aspects considered were:

- The high/low endowment of tourist services on site

- Venues located outside the urban environment or in small urban environments rather than in large cities

Holidays which did not meet these criteria were considered as non-sustainable and thus opposed to those which met them.

\section{Units of Analysis}

Two different units of analysis were used in phase 1 in order to identify and select the possible tourists activities/services: (1) The commercial advertisements published on catalogues and websites of Italian tour operators and travel agencies; (2) The reports of interviews with potential tourists focused on their preferences concerning holiday activities and services.

\section{Content Analysis of Commercial Advertisements}

Sampling method for this unit of analysis was aimed to balance tour operators and travel agencies which proposed nature based and ecotourism holidays for summer 2010, as well as those proposing traditional summer holidays for the same period. Convenience criteria were used for selecting the websites: they were searched for through internet research engines using key words such as "ecotourism holidays", "summer holidays (for traditional holiday). A grid was set up and used in order to collect information from all the advertisements published on websites which offered ecotourism vacations. The grid was used to search for various types of information, including venues, types of accommodations, available activities and available services and the task was to report information on the grid only when it referred to an aspect different from those already recorded. In other words, although the same information (for example, 'hiking trails available nearby', or 'manège and horse riding school on site') could be found on different websites offering ecotourism holidays and/or ads within the same websites, that information was reported only one time on the grid. An identical grid was used to collect the data concerning travel agencies and tour operators offering non-ecotourism or traditional offers. The grids were initially applied to a first pair of websites (one offering ecotourism holidays and the other offering non-ecotourism ones), then another pair of websites was selected and the procedure continued until a saturation point was reached whereby very little new information seemed to be obtained by further analysis. Ten websites ( 5 for ecotourism, 5 for non-ecotourism holidays) were eventually screened.

\section{Content Analysis of Interviews}

A semi-structured questionnaire was built and used for conducting a series of interviews with a convenience sample of potential tourists. Participants were 20 Rome residents (11 males and 9 females) aged between 18 and 68 years. They were interviewed in the public places of the city and some of them were acquaintances of the interviewers. Respondents were asked to imagine to decide how to spend their next summer holidays abroad (i.e., paying holidays, not at relatives' or parents' places) and to specify where they would have liked to go, what kind of accommodation they would have preferred and the activities and services they would have liked to find available on site. Interviews lasted 5 to 10 minutes each and responses where synthetically annotated on a card for each participant. Respondents' gender and age were also recorded on the card. A grid similar to the one used for collecting the information from the websites was applied to search for preferred activities and services in the reports of the interviews. The procedure adopted was also the same. The grid was applied to a first card, then to a second one and the procedure continued until all cards were processed. In this case also, information was added to the grid only when it referred to a different aspect from those already recorded. A saturation point was reached before the last card was scrutinised, leading the authors to stop the interviews.

\section{Results of Phase 1}

Data from the three grids where finally collapsed into a unique list made of non-redundant information. In other words, although an activity/service might have been recorded in more than one grid, it was nevertheless reported only one time on the list. This led to identify about sixty different unique tourism activities and services, which were then re-categorised into sustainable activities/services (i.e., which could be plausibly part of an ecotourism holiday) and unsustainable activities/services (i.e., which could not be plausibly part of an ecotourism holiday) following the criteria previously discussed. Parallel lists of types of venues, accommodations and places to eat were compiled.

\section{Method of Phase 2}

\section{Measurement Instrument}

A structured questionnaire was used in phase 2. Participants were asked to imagine that they had to plan their next summer holiday abroad (lasting at least six days) and were then instructed to indicate how much they would have liked/disliked: 
- Spending their holidays in each of five listed continents; in small versus large urban places and seaside locations; and in the countryside rather than on the mountains

- $\quad$ Finding in the holiday destination each of a set of 27 set of activities and services

- Staying in each of a set of 10 different types of accommodation

- Eating in each of five different facilities/modalities

The options listed were those selected during phase 1 and all responses were recorded on a seven point scale ranging from 1 "I could not stand it at all" to 7 "I would like it a lot".

Other factors measured were: (i) participants' overall appreciation for the presence of tourist facilities in the holiday places (1 single item-five point response scale) and (ii) their general attitudes towards sustainable tourism. This latter aspect was investigated by asking respondents to indicate their agreement/disagreement (1 "completely disagree", to 7 "completely agree") with (7) statements, such as "Vacationers should not be concerned about respecting the local environment, this task should be left to the local authorities" and "During the holiday, it is important to dedicate time to the understanding of the present and past history, culture and traditions of the place visited".

Finally, the instrument included measures of:

- Personal values using Stern and Dietz's (1994) inventory which mentions 11 values representing five main dimensions (altruistic, egoistic, conservative and biospheric values and openness to change). Respondents had to indicate the extent to which each value represented a guiding principle of their life. Response scale ranged from-1 ("opposed to my values") to 5 ("of supreme importance")

- General pro-environmental attitudes using Thompson and Barton (1994) ecocentrism/antropocentrism scale which is composed of 33 likert type items. Twelve items assess participants endorsement of a purely instrumental view of nature and natural resources ("anthropocentric attitude"). Other twelve items measure participants belief that nature has an intrinsic value, which is independent of its contribution to human survival ("ecocentric" attitude). The remaining nine items measure "environmental apathy", or indifference to environmental issues. Respondents had to indicate their degree of agreement/disagreement with each item

A set of social-demographical and residential questions concluded the enquiry.

\section{Participants}

Two-hundred-eighty-two participants (from Rome and Cagliari) were interviewed for this study. The (convenience) sample was approximately balanced by gender (136 males, 146 females) and age (range 18$74 ; M=39.76 ; D S=14.24)$, but resulted in being unbalanced for level of education, with most participants holding a university $(54 \%)$ or high school degree $(32.9 \%)$.

\section{Results}

\section{Principal Axis Factoring}

A PAF (Principal Axis Factoring) analysis performed on the data showed several latent dimensions underpinning participants' preferences for the 27 facilities/activities and services. A three dimensions solution was eventually chosen on the basis of the scree test. These dimensions explained together $39.92 \%$ of the total variance (see Table 1) and were the sole which met the criterion of being composed of at least three items with factor loadings higher than .40 . The first dimension explained $16.05 \%$ of the total variance and was named "culture and nature tourism" as it gathered preferences for types of activities in line with some of the principles of sustainable tourism (relatively low environmental and social impact, attention to both the natural and the cultural features of the tourist location). The second dimension explained $15.01 \%$ of variance and was named "comfort and leisure tourism". This dimension gathered preferences for activities and facilities with high environmental and social impact which are typical of conventional tourism, where leisure and personal comfort are the main goals of the vacation. The third dimension explained $8.85 \%$ of variance and was named "sport and adventure in nature". It gathered preferences for outdoor sport activities, where the physical challenge, rather than the contemplation of nature, appears as the strongest motivating or pushing factor. The PAF also highlighted the existence of activities which can be ascribed to more than one of the three dimensions extracted. For example "hiking" and "excursions" were associated with both the "sport and adventure in nature" form of tourism and also the "culture and nature" form. "Hotel-airport bus connection", "medical centre" and "info points" were associated with both the "culture and nature" dimension and the "comfort and leisure" one. This phenomenon could be due to the existence of people with mixed preferences who appreciated two or more types of vacations. The analyses were then directed to evaluate such a hypothesis. 
Table 1. Mean (M) Standard Deviation (DS) and factor loadings on the 3 extracted factors (F1, F2, F3) of preferences for specific tourism activities/services

\begin{tabular}{|c|c|c|c|c|c|}
\hline & M & DS & F1 & F2 & F3 \\
\hline $\begin{array}{l}\text { Meetings with local inhabitants and artisans to know local usage and costumes } \\
\text { of past and present }\end{array}$ & 5,99 & 1,01 & ,72 & & \\
\hline Guided tours to the local artistic, archeological and historical-cultural sites & 5,98 & 1,01 & ,72 & & \\
\hline Guided tours to the local relevant natural and geological sites & 6,01 & ,97 & ,71 & & \\
\hline Cultural events (theater plays, book presentations, cine-forum, etc.) & 5,41 & 1,17 & 65 & & \\
\hline $\begin{array}{l}\text { Guided tours to the relevant natural and geological local sites such as natural } \\
\text { parks, woods, marine parks, etc. }\end{array}$ & 5,55 & 1,07 & ,61 & & \\
\hline Wine and food tasting courses, ceramics courses, restoration courses. & 5,53 & 1,16 & ,60 & & \\
\hline Traditional fairs & 5,73 & ,98 &, 54 & & \\
\hline Facilities for disabled & 5,96 & 1,27 &, 44 & & \\
\hline Availability of beaches/swimming pools equipped with private beachchairs/umbrellas & 5,21 & 1,58 & & ,77 & \\
\hline Hotel services (es. $24 \mathrm{~h}$ reception, money change, luggage custody ecc.) & 5,55 & 1,12 & &, 67 & \\
\hline Attended car park on site & 5,25 & 1,30 & & 61 & \\
\hline Shopping malls available nearby & 4,37 & 1,41 & & ,58 & \\
\hline Tourist buses available nearby & 5,53 & 1,29 & & ,56 & \\
\hline Fitness center and SPA available on site & 5,17 & 1,34 & & ,53 & \\
\hline Funfairs available nearby & 4,80 & 1,39 & & 49 & \\
\hline Children playgrounds/swimming pools, baby sitting services & 4,54 & 1,36 & & ,37 & \\
\hline Sailing courses opportunities & 5,03 & 1,29 & & &, 77 \\
\hline Underwater fishing opportunities & 4,99 & 1,36 & & &, 74 \\
\hline Availability of motor boat and/or water motorbike rentals & 4,84 & 1,33 & & & ,44 \\
\hline Disco pub and nightspot available. & 4,86 & 1,50 & & & ,41 \\
\hline Tennis courts, golf courses or soccer fields available & 4,66 & 1,25 & & &, 35 \\
\hline Hiking and nordik walking opportunities & 4,99 & 1,32 & 43 & &, 42 \\
\hline Horseback riding and bicycle excursions opportunities & 5,34 & 1,09 & 27 & &, 57 \\
\hline Hotel-Airport bus connection & 6,12 &, 97 & 30 & ,61 & \\
\hline Medical centeravailablenearby & 6,23 & 90 & 44 &, 57 & \\
\hline Infopoints for tourists available nearby & 6,09 & 98 & 48 &, 51 & \\
\hline
\end{tabular}

N.B. Item wording is a translation of that used in the questionnaire. Factor loadings lower than 0.25 were omitted

\section{Bivariate Correlations}

Three aggregated variables corresponding to the latent dimensions underpinning the preferences for activities and services were computed on the basis of the factor loadings (Items with factor loadings lower than. $40 \mathrm{and} /$ or with loadings above 0.25 on more than one variable were excluded from the compute). The pattern of correlations (reported in Table 2) confirms the hypothesis of a general positive relationship between preferences for sustainable forms of tourist activities and pro-environmental attitudes and values and a negative correlation with indifference for environmental issues (apathy). Preferences for "comfort and leisure" activities correlate positively with a quest for tourist facilities, with an anthropocentric view of people-nature relationship and with egoistic values. Preferences for the "sport and adventure in nature" type of activities correlate positively with openness to change and negatively with indifference for environmental issues (apathy) and age. However, some controversial cues were recorded as well. Preferences for the "nature and culture" form of tourist activities show a low but statistically significant correlation with conservatism and with preferences for "comfort and leisure tourism". While the former might be due to the low level of reliability of the conservatism measure, the latter result deserved to be clarified by means of further analyses.

\section{Cluster Analysis}

Participants were clustered on the basis of the three main dimensions of preferences identified by the PAF, plus the set of activities and services that could not be unequivocally classified in the three dimensions (i.e. "hiking", "excursions", "hotel-airport bus connection", "medical centre" and "info points"). These latter were added because they seized aspects not captured by the three main dimensions, which were crucial to distinguish participants on the basis of their assistance necessities. This is the case of preferences for "hotel-airport bus connection", "medical centre" and info points". Preferences for "hiking" and "excursions" instead were included in the analysis in order to better identify groups with mixed preferences. A four-cluster solution was eventually chosen based on the criterion of the relative increase of the agglomeration coefficient and the dendrogram and it was evaluated in the light of the 
results of a set of ANOVA and post hoc tests (see Table 3). Names were given to the clusters on the basis of groups centroids and comparing the results obtained here with those of previous studies.

The first cluster, named "comfort and relax vacationers", identifies participants $(N=88 ; 48$ males, 40 females; mean age $=38.80 ; D S=14.84$ ) with low levels of appreciation for all (or almost all) the activities, services and accommodations. These people show a slight interest for services typical of conventional tourism, for hotels and restaurants and for the presence of a medical centre. Conversely they dislike forms of physically challenging activities such as hiking and tennis, although they might accept some excursions. South America is their most appreciated destination abroad and they prefer villages and towns over countryside and mountains.

The second cluster, named "harder ecotourists", is composed of respondents ( $N=46$; 28 males, 18 females; mean age $=34.59, D S=12,22$ ) with high levels of appreciation for "nature and culture" and for "sport and adventure in nature" activities and the lowest levels of appreciation for the "comfort and leisure" type of options. They like physically challenging activities (hiking), provided they are not typical of conventional forms of tourism (i.e. they like tennis comparatively less). They need few tourist facilities and, as accommodation, they prefer tents, refuges, hostels and bed and breakfasts over hotels and apartments in holiday villages. They like tasting typical local food and prefer homemade food over restaurants. All continents are eligible as destinations for their holidays and, in principle, they do not discriminate between towns and countries.

The third cluster, named "post-modern tourists", is characterised by people $(N=45 ; 21$ males, 24 females; mean age $=38.18, D S=13.68$ ) enthusiastic about all types of services and activities. They enjoy places with many tourist facilities, like holiday villages, but they are also willing to try all sorts of accommodations from tents to hotels. Likewise, they appreciate all sorts of destinations from Europe to Africa and from town to countryside.

Finally the fourth cluster, named "softer ecotourists", refers to participants $(N=103 ; 39$ males, 64 females; mean age $43.57, D S=13.97)$ who appreciate both "culture and nature" and "comfort and leisure" activities. Conversely, they like comparatively less the physically challenging activities of "sport and adventure in nature". Similarly, they are not interested in activities like hiking and tennis, while they prefer places with many facilities for tourists, including medical centres and airport-hotel bus connections. A comfortable hotel or residence room, possibly in a holiday village resort, are preferred over tent or refuge solutions, while restaurants are the best places to eat, better if in the country or in the mountains. Response from this group might be responsible for the low but statistically significant correlation recorded between preferences for "nature and culture" activities and for "comfort and leisure" ones.

Because alternative readings of cluster composition were equally possible, further analyses were needed in order to confirm the initial interpretation. An attempt was thus made to better understand cluster characteristics in light of the other social psychological factors considered in the study.

\section{Clusters Characterization}

Clusters were thus further characterized through Discriminant Analysis (DA) using the following set of psycho-social variables as predictors (In order to reduce the pool of predictors, only those dimensions that correlated significantly with preferences for activities and services were used as predictors in the analysis): "positive attitude towards sustainable tourism", "ecocentrism", "antropocentrism", "apathy" and "altruistic values", "egoistic values", "openness to change" and "biospheric values".

Two significant canonical discriminant functions were found to separate the five clusters (Fig. 1 shows the cluster centroids on the two functions and a summary of DA results). The predictors that best discriminate among the four groups are: "biospheric values", "ecocentrism", "altruistic values", "positive attitude towards ecotourism" and "openness to change" (first discriminant function) and "anthropocentrism" and "apathy" (second discriminant function). An aspect worth noticing is that the four groups differ in relation to the degree of ambivalence of their general environmental orientation and values. Groups 1 and 2 differ considerably from the other two groups in that these people show a substantially coherent ecological view. Indeed, people from group 2 show higher levels of ecocentric and altruistic values and lower levels of anthropocentric and egoistic values; conversely, people of group 1 show lower levels of ecocentrism, altruism, biospheric values and positive attitudes towards sustainable tourism, intermediate levels of anthropocentrism and apathy and higher levels of egoistic values. The remaining two groups appear more inconsistent under this point of view: Group 3 shows high levels of ecocentrism, biospheric values, altruistic values, openness to change and positive attitudes towards sustainable tourism, but it also shows an intermediate level of anthropocentrism. Finally, group 4 shows the highest level of anthropocentrism compared to the other groups, but appears to favour sustainable tourism as well and show high levels of altruism. 
Table 2. Means (M), Standard Deviation (DS), Cronbach's alpha and Pearson's correlations of preferences for tourism activities, attitudes towards sustainable tourism, appreciations of tourism facilities, pro-environmental attitudes, personal values and age

\begin{tabular}{|c|c|c|c|c|c|c|c|c|c|c|c|c|c|c|c|c|}
\hline & $\mathrm{M}$ & DS. 1 & 2 & 3 & 4 & 5 & 6 & 7 & 8 & 9 & 10 & 11 & 12 & 13 & 14 & Age \\
\hline Nature and culture & 5,84 & $\begin{array}{ll}, 74 \quad 0.83 \\
\end{array}$ & -- &, $12^{*}$ & $47^{*}$ & -- & -- &, $42^{* *}$ & -- &,$- 24^{* *}$ & -- &, $44^{* *}$ &, $16^{* *}$ &, $36^{* *}$ & $21^{* *}$ &, 11 \\
\hline Sport and adventure in nature & 4,93 & ,97 & 0.67 & -- & -- & -- & -- & -- &,- 10 &,$- 15^{*}$ & -- & -- &, $18^{* *}$ & -- & -- &,$- 45^{* *}$ \\
\hline Comfort and leisure & 5,13 & ,91 & & 0.8 & -- & 11 & $.57 *$ & -- &, $21^{* *}$ &, $15^{*}$ &, $22^{* *}$ & -- &,$- 12^{*}$ & -- &, $38^{* *}$ &, 11 \\
\hline PosAttsust tour & 5,66 & 1,01 & & & 0.6 &,$- 13^{*}$ & -- &, $47^{* *}$ & -- &,$- 24^{* *}$ & 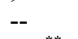 &, $49^{* *}$ &, $16^{* *}$ &, $34^{* *}$ &, $22^{* *}$ & $23^{* *}$ \\
\hline NegAttsust tour & 2,62 & 1,24 & & & & 0.67 & $.12 *$ &,- 11 &, $38^{* *}$ &, $37^{* *}$ &, $31^{* *}$ &,$- 13^{*}$ & -- &,$- 15^{*}$ & -- &, $13^{*}$ \\
\hline Apprtourismservices & 3,40 & 1,02 & & & & & -- & $-.20^{* *}$ & $.15^{*}$ & $.24 * *$ & $.30 * *$ & -- & -- & -- & $.21^{* *}$ & -- \\
\hline Ecocentrism & 3,07 &, 516 & & & & & & 0.76 & -- &,$- 43^{* *}$ & -- &, $55^{* *}$ &, $22^{* *}$ &, $43^{* *}$ &, $25^{* *}$ & -- \\
\hline Anthropocentrism & 1,91 & ,577 & & & & & & & 0.71 &, $42^{* *}$ &, $41^{* *}$ & -- & -- & -- &, $33^{* *}$ &, $28^{* *}$ \\
\hline Apat &, 87 & 615 & & & & & & & & 0.78 &, $26^{* *}$ &,$- 36^{* *}$ &,$- 19^{* *}$ &,$- 31^{* *}$ & -- &, $22^{* * *}$ \\
\hline Egoisticvalues & 1,60 & 1,09 & & & & & & & & & 0.66 & -- &, $27^{* *}$ & -- &, $36^{* *}$ &, $15^{*}$ \\
\hline Biosfericvalues & 3,92 &, 97 & & & & & & & & & & 0.85 & $40^{* *}$ &, $58^{* *}$ &, $35^{* *}$ &, $19^{* *}$ \\
\hline lange & 3,50 & 1,03 & & & & & & & & & & & 0.68 &, $30^{* *}$ & 11 &,$- 14^{*}$ \\
\hline Altrui & 4,41 & ,74 & & & & & & & & & & & & 0.68 &, $34^{* *}$ & -- \\
\hline Conservatism & 3,80 &, 82 & & & & & & & & & & & & & 0.47 &, $33^{* *}$ \\
\hline
\end{tabular}

NB. ${ }^{*} \mathrm{p}<0.05 ; * * \mathrm{p}<0.01$; correlations lower than .10 were omitted; Cronbach's alpha for aggregated variables are reported in diagonal; posAttsust tour = Positive attitudes towards sustainable tourism; negAttsust tour = Negative attitudes towards sustainable tourism; appr. tourism services $=$ Appreciation of tourism places with few/many facilities for tourists

Table 3. Mean differences of preferences for tourism activities and services across the 4 clusters $(\mathrm{C} 1, \mathrm{C} 2, \mathrm{C} 3, \mathrm{C} 4)$

\begin{tabular}{|c|c|c|c|c|c|c|c|c|c|c|c|}
\hline & $\mathrm{C} 1$ & & $\mathrm{C} 2$ & & $\mathrm{C} 3$ & & $\mathrm{C} 4$ & & Total & & $\mathrm{F}$ \\
\hline Culture and Nature* & $5,50 \mathrm{a}$ & $(0,74)$ & $5,93 \mathrm{~b}$ & $(0,68)$ & $6,34 \mathrm{c}$ & $(0,57)$ & $5,87 \mathrm{~b}$ & $(0,70)$ & 5,84 & $(0,74)$ & $\mathrm{F}(3,281)=15,140 ; \mathrm{p}<.001$ \\
\hline Comfort and Leisure* & $4,76 \mathrm{a}$ & $(0,81)$ & $4,43 b$ & $(0,99)$ & $5,54 \mathrm{c}$ & $(0,74)$ & $5,57 \mathrm{c}$ & $(0,67)$ & 5,13 & $(0,91)$ & $\mathrm{F}(3,281)=33,447 ; \mathrm{p}<.001$ \\
\hline Sport and Adventure* & $4,83 \mathrm{a}$ & $(1,00)$ & $5,19 b$ & $(0,83)$ & $5,74 \mathrm{c}$ & $(0,79)$ & $4,56 \mathrm{a}$ & $(0,84)$ & 4,93 & $(0,97)$ & $\mathrm{F}(3,281)=20,504 ; \mathrm{p}<.001$ \\
\hline Hiking & $3,83 \mathrm{a}$ & $(1,12)$ & $6,24 \mathrm{~b}$ & $(0,57)$ & $6,33 b$ & $(0,60)$ & $4,83 \mathrm{c}$ & $(0,85)$ & 4,99 & $(1,32)$ & $\mathrm{F}(3,281)=119,184 ; \mathrm{p}<.001$ \\
\hline Excursions & $4,91 \mathrm{a}$ & $(1,02)$ & $6,11 \mathrm{~b}$ & $(0,64)$ & $6,51 \mathrm{~b}$ & $(0,55)$ & $4,85 \mathrm{a}$ & $(0,89)$ & 5,34 & $(1,09)$ & $\mathrm{F}(3,281)=58,900 ; \mathrm{p}<.001$ \\
\hline Airport bus connection & $5,43 \mathrm{a}$ & $(0,89)$ & $5,48 \mathrm{a}$ & $(1,01)$ & $6,82 \mathrm{~b}$ & $(0,39)$ & $6,68 \mathrm{~b}$ & $(0,53)$ & 6,12 & $(0,97)$ & $\mathrm{F}(3,281)=71,049 ; \mathrm{p}<.001$ \\
\hline Medical center & $5,73 \mathrm{a}$ & $(0,94)$ & $5,63 \mathrm{a}$ & $(0,85)$ & $6,78 \mathrm{~b}$ & $(0,47)$ & $6,72 \mathrm{~b}$ & $(0,53)$ & 6,24 & $(0,90)$ & $\mathrm{F}(3,281)=47,844 ; \mathrm{p}<.001$ \\
\hline Infopoints & $5,63 \mathrm{a}$ & $(1,03)$ & $5,26 \mathrm{a}$ & $(0,88)$ & $6,76 \mathrm{~b}$ & $(0,43)$ & $6,56 \mathrm{~b}$ & $(0,64)$ & 6,09 & $(0,98)$ & $\mathrm{F}(3,281)=48,983 ; \mathrm{p}<.001$ \\
\hline ervices $^{\wedge}$ & $3,20 \mathrm{a}$ & & $3,00 \mathrm{a}$ & & $3,63 \mathrm{~b}$ & $(0,99)$ & $3,64 \mathrm{~b}$ & $0,89)$ & 3,40 & $(1,02)$ & $\mathrm{F}(3,279)=6,569 ; \mathrm{p}<.001$ \\
\hline Hostel & $4,38 \mathrm{a}$ & & $5,42 \mathrm{~b}$ & & $5,22 \mathrm{~b}$ & $(1,57)$ & $4,10 \mathrm{a}$ & & 4,58 & & $\mathrm{~F}(3,280)=10,738 ; \mathrm{p}<.001$ \\
\hline bandb & $5,25 \mathrm{a}$ & $(1,22)$ & $5,43 \mathrm{a}$ & $(0$, & $5,82 \mathrm{~b}$ & $(1,05)$ & $5,14 a$ & $(1,21)$ & 5,33 & $(1,17)$ & $\mathrm{F}(3,281)=3,986 ; \mathrm{p}=.008$ \\
\hline Room for rent & $5,03 \mathrm{a}$ & $(1,71)$ & $5,78 \mathrm{~b}$ & $(1,2$ & $6,09 \mathrm{c}$ & $(1,04)$ & $5,04 \mathrm{a}$ & $(1,49)$ & 5,33 & $(1,52)$ & $\mathrm{F}(3,281)=8,020 ; \mathrm{p}<.001$ \\
\hline Tent & $3,90 \mathrm{a}$ & $(1,90)$ & $5,20 \mathrm{~b}$ & $(1,69)$ & $4,58 \mathrm{~b}$ & $(1,76)$ & $3,21 \mathrm{a}$ & $(1,65)$ & 3,97 & $(1,89)$ & $\mathrm{F}(3,281)=15,644 ; \mathrm{p}<.001$ \\
\hline Camper/bungalow & $4,35 \mathrm{a}$ & $(1,71)$ & $5,26 \mathrm{~b}$ & $(1,48)$ & $4,84 \mathrm{a}$ & $(1,66)$ & $3,99 \mathrm{c}$ & $(1,64)$ & 4,45 & $(1,70)$ & $\mathrm{F}(3,281)=7,396 ; \mathrm{p}<.001$ \\
\hline Hotel & $5,35 \mathrm{a}$ & $(1$, & $4,85 b$ & & $5,91 \mathrm{c}$ & $(1,22)$ & $6,02 \mathrm{c}$ & $(0,96)$ & 5,60 & $(1,22)$ & $F(3,281)=13,586 ; p<.001$ \\
\hline Apartı & $4,42 \mathrm{a}$ & $(1,53)$ & $3,85 \mathrm{a}$ & $(1,74)$ & $4,98 \mathrm{~b}$ & $(1,96)$ & $5,17 \mathrm{~b}$ & $(1,50)$ & 4,69 & $(1,69)$ & $\mathrm{F}(3,281)=8,415 ; \mathrm{p}<.001$ \\
\hline Resta & $5,43 \mathrm{a}$ & $(1,31)$ & $5,24 \mathrm{~b}$ & $(1,59)$ & $5,98 \mathrm{a}$ & $(1,20)$ & $5,79 a$ & 1) & 5,62 & $(1,29)$ & $\mathrm{F}(3,281)=3,770 ; \mathrm{p}=.011$ \\
\hline Loca & $5,83 \mathrm{a}$ & $(1,05)$ & $6,15 b$ & $(0,89)$ & $6,33 \mathrm{~b}$ & $(0,90)$ & $6,15 b$ & ,83) & 6,08 & $(0,94)$ & $\mathrm{F}(3,281)=3,522 ; \mathrm{p}=.016$ \\
\hline de food & $5,06 \mathrm{a}$ & $(1,41)$ & $5,72 \mathrm{~b}$ & $(1,49)$ & $5,56 \mathrm{~b}$ & $(0,99)$ & $5,26 \mathrm{a}$ & $(1,20)$ & 5,32 & $(1,30)$ & $\mathrm{F}(3,281)=3,526 ; \mathrm{p}=.022$ \\
\hline Тур & $6,00 \mathrm{a}$ & & $6,63 b$ & & $6,47 \mathrm{~b}$ & $(1,10)$ & $6,07 \mathrm{a}$ & & 6,20 & & $=5,550 ; \mathrm{p}=.001$ \\
\hline $\mathrm{Na}$ & $4,40 \mathrm{a}$ & $(1$, & ,13a & & $4,62 \mathrm{a}$ & 9) & $5,19 \mathrm{~b}$ & 2) & 4,68 & $(1,75)$ & $\mathrm{F}(3,281)=5,477 ; \mathrm{p}=.001$ \\
\hline alfood & $4,78 \mathrm{a}$ & & 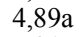 & & $5,44 \mathrm{~b}$ & & $5,06 \mathrm{a}$ & & 5,0 & & $9 ; p=.028$ \\
\hline & $5,57 \mathrm{a}$ & & a & & $6,27 \mathrm{~b}$ & ) & $5,96 \mathrm{a}$ & & 5,8 & $(0,99)$ & $1 ; p=.001$ \\
\hline & $5,49 \mathrm{a}$ & & 5 , & & $6,24 \mathrm{~b}$ & & 5,7 & & 5, & & $; \mathrm{p}<.01$ \\
\hline rica & $582 \mathrm{a}$ & & $6,37 \mathrm{~b}$ & & $6,51 \mathrm{c}$ & & 5,5 & & 5,90 & 4) & $97 ; \mathrm{p}<.001$ \\
\hline Afr & 5 & & 6 & & 6, & & & & 5 & 2) & $2 ; \mathrm{p}<.001$ \\
\hline As & 5,18 & $(1,4$ & & & & & & & 5,33 & & $\mathrm{~F}(3,281)=3,927 ; \mathrm{p}=.009$ \\
\hline & 4,70 & & & & $5,49 \mathrm{~b}$ & & $5,08 \mathrm{c}$ & & 5,15 & & $\mathrm{~F}(3,281)=9,778 ; \mathrm{p}<.001$ \\
\hline Tow & $4,67 a$ & & & & $5,64 \mathrm{~b}$ & ) & $5,16 \mathrm{c}$ & & 5,11 & $(1,28)$ & $79 ; \mathrm{p}<.001$ \\
\hline Mountain & $4,58 \mathrm{a}$ & $(1,65)$ & $5,91 \mathrm{~b}$ & $(0,89)$ & $6,00 \mathrm{~b}$ & $(1,15)$ & $5,41 \mathrm{c}$ & $(1,18)$ & 5,33 & $(1,41)$ & $\mathrm{F}(3,281)=16,817 ; \mathrm{p}<.001$ \\
\hline Count & $4,27 \mathrm{a}$ & $(1,6$ & $5,59 \mathrm{~b}$ & $(1,1$ & $5,64 \mathrm{~b}$ & $(1,30)$ & $5,00 \mathrm{~b}$ & & 4,97 & $(1,51)$ & $F(3,281)=13,310 ; p<.001$ \\
\hline Nationalholid: & $3,48 \mathrm{a}$ & $(1,72)$ & $3,61 \mathrm{a}$ & $(1,79)$ & $4,04 \mathrm{a}$ & $(1,98)$ & $4,51 \mathrm{~b}$ & $(1,60)$ & 3,97 & $(1,78)$ & $\mathrm{F}(3,281)=6,474 ; \mathrm{p}<.001$ \\
\hline
\end{tabular}

Note: $\mathrm{N}=282$; variables in italics are those used in the cluster analysis; ${ }^{*}$ aggregated variable constructed on the base of the PFA; ' 'Overall appreciation for places with many/few tourism facilities'; standard deviations are reported in parentheses; only preferences for which clusters differ significantly are reported; means with same letter do not differ statistically

If we match these results with the groups' characterisation in terms of tourism preference we can conclude that the low levels of pro-environmental attitudes recorded for group 1 parallel their favour towards more traditional (and thus high impact) holidays. Conversely, the high levels of proenvironmental attitudes and values recorded for group 2 parallel the interest of these people for low-impact tourist activities. The incoherence in attitudes and values recorded for groups 3 and 4 is instead coherent with their tourist preferences which are capable of combining lowand high-impact tourism activities in the same holiday. Indeed, Group 3 and 4 differ mostly in terms of their relative appreciation for sport activities and for certain kinds of comforts. The correlation recorded between preferences for "culture and nature" and for "comfort and leisure activities" might be due to the responses of these particular groups of respondents. 


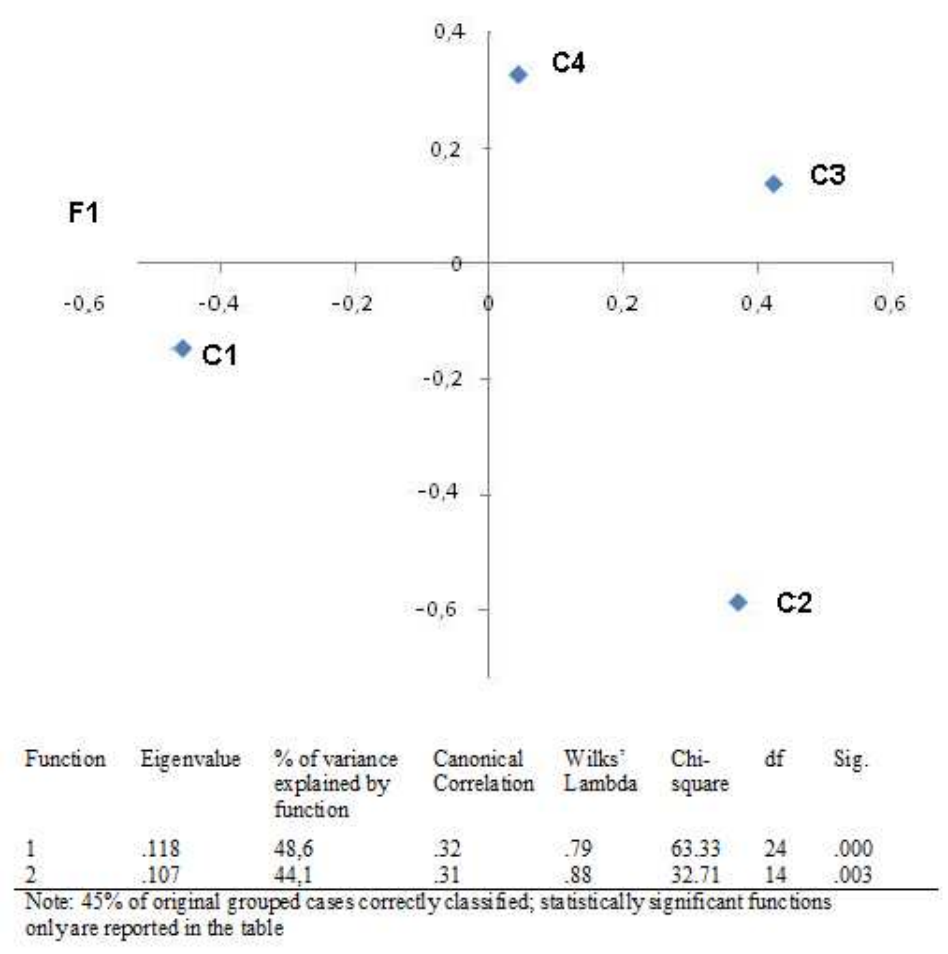

Fig. 1. Cluster means on the two discriminant functions and summary of the discriminant analysis results. Note: $F 1=$ ecocentric $\&$ altruistic values; F2 = anthropocentric \& egoistic values; $\mathrm{C} 1=$ cluster 1: 'comfort\& relax vacationers'; C2 = cluster 2: 'harder ecotourists'; C3 = 'post-modern tourists' ; C4 = 'softer ecotourists

\section{Discussion and Conclusion}

\section{Theoretical and Methodological Considerations}

All in all, our data confirmed that people who hold pro-environmental values and attitudes (both general and specific) tend in general to prefer more sustainable tourism activities and services. Nevertheless, there is also evidence that such association could vary across people. Indeed, here we noted the existence of groups of people whose tourism preferences are consistent with their environmental attitudes, while inconsistencies between attitudes and tourism preferences emerged for other groups. Reasons for such inconsistencies are unclear at the moment. Previous studies suggested that, in the environmental domain, coherence between attitudes and behavioural choices cannot be taken for granted and this for at least two reasons (Castro et al., 2009; Bonnes et al., 2011). The first is of a methodological nature and concerns the difficulties to set up measurement instruments of environmental attitudes and values which are able to accurately grasp the various facets of such constructs. In this sense, for example, proenvironmental attitudes are often considered monodimensional, whereas their structure is likely to be multidimensional (Bonnes et al., 2011; Franson and Gärling, 1999). In our case, we used a three dimensional instrument to measure attitudes and a five dimensional one to measure values, but we cannot be sure that they have grasped all dimensions which could be crucial for understanding tourism choices. Future studies could use more updated instruments, such as Corral-Verdugo and colleagues' NHIP scale (Corral-Verdugo et al., 2008) for measuring environmental attitudes, while values could be assessed using instruments more relevant for the tourism domain (see for eg. Crick-Furman and Prentice, 2000) and, for example, which take into account the hedonistic dimension (Steg et al., 2014). A similar consideration can be put forward for the ad-hoc instruments we used to measure both the specific attitudes towards sustainable tourism and tourism preferences. These instruments need to be refined because the variance explained by the three dimensions of tourism preference is still limited. Data analysis suggested that more activities could be added and/or the existing ones could be grouped differently in order to better identify other dimensions and explain more variance. However, another reason for the recorded inconsistencies might be the complex nature of environmental issues and environmentally relevant behaviours. These often raise the dilemma of how to reconcile the individual aspirations to satisfy personal needs and motivations with the increasing number of limitations imposed to the use of natural (and human) resources. Overall, while everybody generally agrees with the idea that environmental and social resources should be managed in a more sustainable manner, not everyone is also then willing 
to sacrifice their personal necessities and expectations in order to achieve such sustainability (Bonnes et al., 2011). Hence by transferring this to the tourism domain it could be said that, if one of the main pushing factors that prompts people to go on holiday is their willingness to take a break from everyday problems and routines, for some people (independently of their declared pro-environmental attitudes), going on holiday also means to take a break from their social and environmental responsibilities. This also suggests a possible role for normative factors. Future studies should for example assess the role of the individual's willingness to comply with social norms, because these factors have already been shown to affect individual ecological behaviour even in the tourism domain (Brown et al., 2010). Nevertheless, other factors could also explain the attitude-preference inconsistencies recorded here. One such factor could be the level of knowledge concerning the actual environmental and social impact of individual tourist choices. No measure of such knowledge was used in our study, so it is impossible to verify whether our participants were or were not informed of the relative social and environmental impact of the various tourist activities listed. Clearly, if a person is unaware of the problems that his/her decisions can cause to the environment, he/she cannot make the requested proenvironmental choices, even when his/her attitudes strongly favor sustainability. Previous findings have indicated that, in some cases, the levels of awareness of the environmental and social impact of tourism and ecotourism may be low among the general public (Cini, 2008; Sangpikul and Batra, 2007). This might due to the difficulty in unequivocally distinguishing sustainable and unsustainable activities in the tourism domain and/or to a lack of communication campaigns directed to potential tourists. Finally, tourist preferences have proven to be affected by various personality traits which, for example, have shown to be able to prompt towards more adventurous and challenging or, conversely, more familiar and reassuring tourist experiences (Frew and Shaw, 1999; Hoxster and Lester, 1988; Plog, 1987). At the moment it is unclear whether and how proenvironmental values and attitudes could interact with personality traits in determining tourist choices, but it is sensible to expect some kinds of inconsistencies when personal values and attitudes are at odds with one's own stable traits and inclinations. In this sense, it would be sensible if tourism preferences were investigated using more comprehensive theoretical models that are able to relate them to other aspects, such as past behaviour (or habits) and behavioural intentions.

\section{Practical and Managerial Implications}

From a managerial point of view, our results confirm that people who participate in ecotourism vacations tend to be pushed by a variety of motivational factors which, in turn, can drive different kinds of expectations. Some people look for adventurous and physically challenging experiences, others look for pure and relaxing environments and others for natural and cultural discoveries. However, our results add to the existing literature because they suggest the importance of not mistaking the appreciation of activities in natural environments with a strong pro-environmental concern. Although such a relationship exists in many cases, it is not always so. For example, there is evidence that the "most natural environments" may not always raise the highest preferences and acceptance by people. Indeed, in some cases, they may appear as less attractive and comfortable than other "less natural environments" in which nature is well-kept and clean or "humanised" (Williams and Cary, 2002). Thus, from a managerial point of view, in the organisation and promotion of ecotourism holidays, greater attention should be devoted to the existence of these differences in expectations and needs, as they might affect the individual choices and satisfaction.

In the meantime, it is important that the management of ecotourism takes into account not only the issues of customer attraction and satisfaction, but also those of social and environmental ethics. According to the ecotourism tenets, for example, ecotourism holidays should also lead to a deeper transformation of tourists' knowledge, attitudes, values and behaviours regarding sustainability (Donohoe and Needham, 2006; Fennell, 2003; Tisdell and Wilson, 2001). Understanding tourists' differences in proenvironmental values and attitudes can thus also be of help in this sense. Previous discussions concerning the educational implications of sustainable tourism have led to specific practical proposals (Weaver, 2005). In particular, it might be advisable to tailor the educational intervention to the actual characteristics of the target learners. If we take into account the specific results obtained here, for example, we could draw different expectations for each cluster of tourists identified. In particular, for instance, people of cluster 1 ("comfort and relax vacationers") could be attracted by those ecotourism holidays that are perceived as offering comfortable and relaxing experiences. In this case, however, once on site, they are unlikely to behave coherently with the sustainability principles, as they showed the lowest scores on ecocentrism and altruistic values and the highest in apathy (indifference towards ecological issues) and egoistic values. These people would thus need specific educational intervention aimed at enhancing their general pro-environmental and social values and attitudes. People of cluster 2 ("harder ecotourists") instead are very likely to choose an ecotourism vacation, because they dislike conventional forms of tourism and are attracted by the physically challenging activities in nature that ecotourism could offer. They hold strong general pro-environmental and social values and thus should not need an educational intervention focused on such factors. Yet, these people scored high on appreciation for the activities of the "sport and adventure in nature" factor, whereas not all of these activities are ecologically and socially 
sustainable. Thus, an educational intervention directed to this people should aim at broadening their understanding and awareness of the importance of respecting all features of the surrounding environment (and not just some of them). People of cluster 4 ("softer ecotourists") could also choose an ecotourism vacation, but their interests towards it differ substantially from "harder ecotourists". "Softer ecotourists" are not attracted by the adventurous side of ecotourism; rather, they are focused on the environmental and social quality that it offers. Nature, culture and art are valued options in their tourism experience, provided these do not imply sacrificing personal comfort and relaxation. The higher levels of anthropocentrism recorded for this group suggest that these people are not interested in nature protection per se, but they might see it as a function of human needs and aspirations. Educational interventions for this group should focus, first, on enhancing their general altruistic and ecocentric view of ecological issues and subsequently address the specific issues of sustainability in tourism. Finally, it is difficult to draw specific expectations concerning the third cluster ("post-modern tourists"). As they appeared enthusiastic about any option presented to them, they might find themselves involved in an ecotourism vacation sooner or later. They scored high on ecocentrism and altruistic values, which might indicate a certain attention to social and environmental issues, but their preference for both high-and low-impact tourist activities confirm that ecological issues are not used as parameters to choose their vacation. They might not need an educational intervention which involves general ecological and social values and attitudes, but they might take advantage of an educational intervention focused on the importance of also considering social/ecological issues on holidays.

All in all, such results indicate that by segmenting the potential tourists on the basis of both their tourism preferences and pro-environmental values it is possible to design management strategies directed to attract the attention of different types of tourists and meet their specific expectations. In the meantime, however, more attention can also be directed to meet the educational needs concerning sustainability of these same tourists.

\section{Author's Contributions}

Paola Passafaro and Francesca Cini: Were responsible for the planning of the study, literature review, building of the measurement instrument, coordination of data collection, data analysis and writing of the draft of the manuscript.

Vittoria Diaco, Ornella Schirru, Aurora Boison, Virginia Gasparri and Simona Giannantoni: All contributed to building the measurement instrument, data collection, data record, data analysis, results discussion and writing of the draft of the manuscript.

\section{Ethics}

This article is original and contains unpublished material. The corresponding author confirms that all of the other authors have read and approved the manuscript and no ethical issues involved.

\section{References}

Archer, D. and S. Wearing, 2002. Interpretation and marketing as management tools in National Parks: Insights from Australia. J. Leisure Property, 2: 29-40. DOI: $10.1057 /$ palgrave.rlp.5090137

Bamberg, S. and G. Möser, 2007. Twenty years after Hines, Hungerford and Tomera: A new meta-analysis of psycho-social determinants of pro-environmental behaviour. J. Environmental Psychol., 27: 14-25. DOI: 10.1016/j.jenvp.2006.12.002

Beh, A.W. and B.L. Bruyere, 2007. Segmentation by visitor motivation in three Kenyan national reserves. Tourism Management, 28: 1464-1471.

DOI: $10.1016 /$ j.tourman.2007.01.010

Berto, R., 2005. Exposure to restorative environments helps restore attentional capacity. J. Environ. Psychol., 25: 249-259. DOI: 10.1016/j.jenvp.2005.07.001

Blamey, R.K. and V.A. Braithwaite, 1997. A social values segmentation of the potential ecotourism market. J. Sustainable Tourism, 5: 29-45. DOI: $10.1080 / 09669589708667274$

Bonnes, M., P. Passafaro and G. Carrus, 2011. The ambivalence of attitudes toward urban green areas: Between pro-environmental worldviews and daily residential experience. Environ. Behavior, 43: 207-232. DOI: 10.1177/0013916509354699

Bramwell, B. and B. Lane, 1993. Sustainable tourism: an evolving global approach. J. Sustainable Tourism, 1: 1-5. DOI: $10.1080 / 09669589309450696$

Brown, T.J., S.H. Ham and M. Hughes, 2010. Picking up litter: An application of theory-based communication to influence tourist behaviour in protected areas. J. Sustainable Tourism, 18: 879-900. DOI: $10.1080 / 09669581003721281$

Butler, J.R. and G.D. Fenton, 1987. Bird watchers of Point Pelee National Park, Canada: Their characteristics and activities with special consideration to their social and resource impacts. Alberta Naturalist, 17: 135-146.

Castro, P., M. Garrido, E. Reis and J. Menezes, 2009. Ambivalence and conservation behaviour: An exploratory study on the recycling of metal cans. J. Environ. Psychol., 29: 24-33. DOI: 10.1016/j.jenvp.2008.11.003

Cini, F., 2008. Promuovere l'ecoturismo. Una strategia di marketing sociale [Promoting ecotourism. A social marketing strategy]. Acireale-Roma: Bonanno Editore. 
Cini, F., L. Leone and P. Passafaro, 2012. Promoting ecotourism among young people: A segmentation strategy. Environ. Behav., 44: 87-106. DOI: $10.1177 / 0013916510389313$

Cohen, E.H., 1974. Who is a tourist?: A conceptual clarification. Sociological Rev., 22: 527-555. DOI: $10.1111 / \mathrm{j} .1467-954 X .1974 . t b 00507 . x$

Cohen, E.H., 2004. Contemporary Tourism: Diversity and Change. 1st Edn., Elsevier, Boston.

Corral-Verdugo, V., G. Carrus, M. Bonnes, G. Moser and J.B.P. Sinha, 2008. Environmental beliefs and endorsement of sustainable development principles in water conservation: Toward a new human interdependence paradigm scale. Environ. Behav., 40: 703-725. DOI: 10.1177/0013916507308786

Crick-Furman, D. and R. Prentice, 2000. Modeling tourists' multiple values. Annals Tourism Res., 27: 69-92.

Crompton, J., 1979. Motivations for pleasure vacation. Annals Tourism Res., 6: 408-424. DOI: 10.1016/0160-7383(79)90004-5

Finisterra do Paco, A.M. and Barata Raposo, 2010. Green consumer market segmentation: Empirical findings from Portugal. Int. J. Consumer Studies, 34: 429-436. DOI: $10.1111 / \mathrm{j} .1470-6431.2010 .00869 . \mathrm{x}$

Diamantis, D., 1998. Consumer behavior and ecotourism products. Annals Tourism Res., 25: 516- 528. DOI: 10.1016/S0160-7383(97)00076-5

Dolnicar, S. and F. Leisch, 2008. Selective marketing for environmentally sustainable tourism. Tourism Management, 29: 672- 680. DOI: $10.1016 /$ j.tourman.2007.07.010

Donohoe, H.M. and R.D. Needham, 2006. Ecotourism: The evolving contemporary definition. J. Ecotourism, 3: 192-210. DOI: 10.2167/joe152.0

Donohoe, H.M. and X. Lu, 2009. Universal tenets or diametrical differences? An analysis of ecotourism definitions from China and Abroad. Int. J. Tourism Res., 11: 357- 372. DOI: 10.1002/jtr.697

Fennell, D., 2003. Ecotourism: An Introduction (2End.). London: Routledge.

Franson, N. and T. Gärling, 1999. Environmental concern: Conceptual definitions, measurements methods and research findings. J. Environmental Psychol., 19: 369-382. DOI: 10.1006/jevp.1999.0141

Frew, E.A. and R.N. Shaw, 1999. The relationship between personality, gender and tourism behaviour. Tourism Management, 20: 193-202. DOI: $10.1016 / \mathrm{S} 0261-5177(98) 00081-8$

Galley, G. and J. Clifton, 2004. The motivational and demographic characteristics of research ecotourists: Operation Wallacea volunteers in South-East Sulawesi, Indonesia. J. Ecotourism, 3: 69-82. DOI: $10.1080 / 14724040408668150$
Galloway, G., 2002. Psychographic segmentation of park visitor markets: Evidence for the utility of sensation seeking. Tourism Management, 23: 581-596. DOI: $10.1016 / \mathrm{S} 0261-5177(02) 00025-0$

Gilmore, A. and G. Simmons, 2007. Integrating sustainable tourism and marketing management: Can national parks provide the framework for strategic change? Strategic Change, 16: 191-200. DOI: $10.1002 /$ jsc. 798

Hardy, A.L. and R.J.S. Beeton, 2009. Sustainable tourism or maintainable tourism: Managing resources for more than average outcomes. J. Sustainable Tourism, 9: 168-192. DOI: 10.1080/09669580108667397

Hartig, T., 2004. Restorative Environments. In: Encyclopedia of Applied Psychology, C. Spielberger (Ed.), Academic Press, San Diego, pp: 273-278.

Henwood, K. and N. Pidgeon, 2001. Talk about woods and trees: threat of urbanization, stability and biodiversity. J. Environ. Psychol., 21: 125-147. DOI: $10.1006 /$ jevp.2000.0196

Hoxster, A.L. and D. Lester, 1988. Tourist behaviour and personality. Personality Individual Differences, 9: 177-178. DOI: 10.1016/0191-8869(88)90045-1

Howestine, E., 1993. Market segmentation for recycling. Environ. Behavior, 25: 86-102. DOI: $10.1177 / 0013916593251004$

Hvenegaard, G.T. and P. Dearden, 1998. Ecotourism versus tourism in a Thai national park. Annals Tourism Res., 25: 700-720. DOI: 10.1016/S0160-7383(98)00020-6

Hunter, C., 1997. Sustainable tourism as an adaptive paradigm. Annals Tourism Res. 24: 850-867. DOI: 10.1016/S0160-7383(97)00036-4

Jesson, J., 2009. Household waste recycling behavior: A market segmentation model. Social Marketing Q., 15: 25-39. DOI: $10.1080 / 15245000902957326$

Kaplan, R. and S. Kaplan, 1989. The Experience of Nature: A Psychological Perspective. New York: Cambridge University Press.

Kibicho, W., 2006. Tourists to Amboseli National Park: a factor-cluster segmentation analysis. J. Vacation Marketing, 12: 218-231. DOI: $10.1177 / 1356766706064618$

Kim, K., G. Jogaratnam and J. Noh, 2006. Travel decisions of students at a US university: Segmenting the international market. J. Vacation Marketing, 12: 345-357. DOI: $10.1177 / 1356766706067606$

Korpela, K., M. Kytta and T. Hartig, 2002. Restorative experiences, self-regulation and children's place preferences. J. Environ. Psychol., 22: 387-398.

DOI: $10.1006 /$ jevp.2002.0277 
Kotler, P., 1982. Marketing for Nonprofit Organizations. 1st Edn., Yuan Shan Book Company, Taipei, pp: 528.

Kotler, P. and E.L. Roberto 1989. Social Marketing: Strategies for Changing Public Behaviour. 1st Edn., Free Press, New York.

Laarman, J.G. and P.B. Durst, 1987. International forestry: Nature travel in the Tropics. J. Forestry, 85: 43-46.

Lindberg, K., 1991. Economic policies for maximizing nature tourism's contribution to sustainable development. Washington, DC: World Resour, Inst.

Marques, C., E. Reis and J. Menezes, 2010. Profiling the segments of visitors to Portuguese protected areas. J. Sustainable Tourism, 18: 971-996.

DOI: 10.1080/09669582.2010.497222

McFarlane, B.L. and P.C. Boxall, 1996. Participation in wildlife conservation by birdwatchers. Human Dimensions Wildlife, 1: 1-14.

DOI: $10.1080 / 10871209609359066$

McKenzie-Mohr, D., 2000a. Fostering sustainable behavior through community based social marketing. Am. Psychol., 55: 531-537.

McKenzie-Mohr, D., 2000b. Promoting sustainable behavior: an introduction to community based social marketing. Am. Psychol., 56: 543-554.

Pearce, P.L. and J. Packer, 2013. Minds on the move: New links from psychology to tourism. Annals Tourism Res., 40: 386-411.

DOI: $10.1016 / \mathrm{j}$.annals.2012.10.002

Plog, S., 1987. Understanding Psychographics in Tourism Research. In: Travel, Tourism and Hospitality Research, Ritchie, R. and C. Goeldner, (Eds.), Wiley, New York, pp: 203-14.

Sangpikul, A and A. Batra, 2007. Ecotourism: A perspective from Thai youth. J. Hospitality, Leisure, Sport Tourism Education, 6: 81-85.

Scopelliti, M. and M.V. Giuliani, 2004. Choosing restorative environments across the lifespan: A matter of place experience. J. Environ. Psychol., 24: 423-437. DOI: 10.1016/j.jenvp.2004.11.002

Scopelliti, M. and M.V. Giuliani, 2005. Restorative environments in later life. An approach to wellbeing from the perspective of environmental psychology. J. Housing Elderly, 19: 205-228.

Shah, K., J. McHarry and R. Gardiner 2002. Economic briefing No 4: Sustainable tourism briefing paper: UNEP. Stakeholder Forum's Towards Earth Summit.

Staats, H., 2003. Understanding Proenvironmental Attitudes and Behaviour: An Analysis and Review of Research Based on the Theory of Planned Behaviour. In: Psychological Theories for Environmental Issues, Bonnes, M., T. Lee, M. Bonaiuto (Eds.), Aldershot, GB: Ashgate, pp: 171-202.

Steg, L., G. Perlaviciute, E. van der Werff and J. Lurvink, 2014. The significance of hedonic values for environmentally relevant attitudes, preferences and actions. Environ. Behav., 46: 163-192.

DOI: $10.1177 / 0013916512454730$
Stern, P.C., 2000. Toward a coherent theory of environmentally significant behavior. J. Social Issues, 56: 407-424.

Stern P.C. and T. Dietz, 1994. The value basis of environmental concern. J. Social Issues, 50: 65-84. DOI: $10.1111 /$ j.1540-4560.1994.tb02420.x

Tabanico, J.J. and P.W. Schultz, 2007. Community based social marketing. BioCycle, 48: 41-44.

Thompson, S.G.C. and M.A. Barton, 1994. Ecocentric and anthropocentric attitudes toward the environment. J. Environ. Psychol., 14: 149-157. DOI: $10.1016 / \mathrm{S} 0272-4944(05) 80168-9$

Tisdell, C. and C. Wilson, 2001. Wildlife-based tourism and increased support for nature conservation financially and otherwise: Evidence from sea turtles ecotourism at Mon Repos. Tourism Economics, 7: 233-249. DOI: 10.5367/000000001101297847

Uysal, M., C. Jurowski, F.P. Noe and C.D. McDonald, 1994. Environmental attitude by trip and visitor characteristics: US virgin islands national park. Tourism Manage., 15: 284-294. DOI: 10.1016/0261-5177(94)90046-9

UNWTO, 2001. Global Forecasts and Profiles of Market Segments. United Nations World Tourism Organization.

UNWTO, 2002. Sustainable development of ecotourism: A compilation of good practices. United Nations World Tourism Organization.

UNWTO, 2007. Davos declaration on climate changes and tourism-responding to global challenges. United Nations World Tourism Organization.

Weaver, D.B., 2005. Comprehensive and minimalist dimensions of ecotourism. Annals Tourism Res., 32: 439-455. DOI: 10.1016/j.annals.2004.08.003

Weaver, D.B. and L.J. Lawton, 2002. Overnight ecotourist market segmentation in the Gold Coast hinterland of Australia. J. Travel Res., 40: 270-280. DOI: $10.1177 / 004728750204000305$

Weaver, D.B. and L.J. Lawton, 2007. Twenty years on: The state of contemporary ecotourism research. Tourism Management, 28: 1168-1179. DOI: 10.1016/j.tourman.2007.03.004

Weiler, B. and H. Richins, 1995. Extreme, extravagant and elite: A profile of ecotourists on Earthwatch expeditions. Tourism Res., 20: 29-36. DOI: $10.1080 / 02508281.1995 .11014730$

Williams, K.J.H. and J. Cary, 2002. Landscape preferences, ecological quality and biodiversity protection. Environ. Behav., 34: 257-274. DOI: $10.1177 / 0013916502034002006$

WTTC and UNWTO, 1996. Agenda 21 for the travel and tourism industry towards environmentally sustainable development. World Travel and Tourism Council, World Tourism Organization and the Earth Council. 